\title{
The cue for disjunctive and conjugate eye movements
}

\author{
F. M. TOATES \\ Laboratory of Experimental Psychology, University of Sussex
}

The principles of control theory have been extensively applied to vision and have aide $\frac{0}{\Phi}$. the understanding of the pupillary light reflex (Stark and Sherman, 1957), accommodation (Campbell and Westheimer, 1960; Stark, Takahashi, and Zames, 1965), and conjugate tracking movements (Fender, 1964; Westheimer, 1954; Young and Stark, 1963). Quanస titative analyses were carried out, and mathematical models suggested which attempte\& to explain performance. Although some work has been done on convergence movements (Westheimer and Mitchell, 1956; Rashbass and Westheimer, I96ra), this system has sङ far evaded representation in control engineering terms.

If an object moves in a horizontal plane across a subject's field of vision, the eyes arø called upon to make a parallel or, as it is sometimes called, conjugate movement, in order that the image may continue to fall on the fovea of each eye. Both eyes move togethee in the same direction. The other basic movement in the horizontal plane is a disjunctive or convergence movement. In this case the eyes rotate inwards as an object is broughg nearer.

A mathematical analysis was carried out (Fender and Nye, $196 \mathrm{I})$ into conjugate eyह movements, based on the fact that disparity of the image from the fovea is the cue for an eye् movement. The disparity-actuated negative feedback system operates so as to eliminat 庖 error between fovea and image. If the image of the object is shifted through an angle 0. with respect to the eye, then the image is displaced $R \theta$ on the retina away from the foveao $R$ being the distance between the retina and the eye's centre of rotation.

Since the need to fix an image on the fovea is also the cue for convergence (Alperno 1962, p. 99), an equation similar to that proposed by Fender and Nye should also be् applicable to this system. Fig. I shows an unambiguous system of error detection whiclg it is proposed that the eye employs for conjugate and disjunctive movements. A signam proportional to the distance $P$ is taken and is added to a corresponding signal from the other eye proportional to $Q . \quad Q$ and $P$ are simply the distances in each eye between the్ fovea and the image (or feature of maximum interest in a large image). A signal pron portional to $P-Q$ is the cue for a convergence movement.

When a pure convergence movement is to be executed, the value of $P+Q$, the cue for conjugate movement, is zero. Likewise $P-Q$ is zero when a pure conjugate movement io called for. On this basis the eye has all the information available for carrying out con vergence, divergence, and left and right conjugate movements, as well as for a composite movement. The muscles of each eye always receive an equal innervation, and this accords with Hering's law of equal innervation. The net movement is simply the sum o $\mathbb{\mathscr { B }}$ disjunctive and conjugate components. That this in fact occurs for any complex targe $\overrightarrow{\mathbb{B}}$ movement was shown by Rashbass and Westheimer ( $196 \mathrm{rb}$ ). 

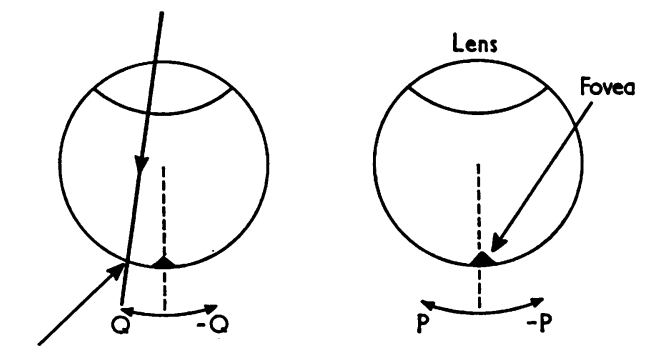

FIG. I Notation used in model to describe retinal disparity

Point image or feature of image of maximum interest

The model makes some interesting predictions concerning the effect of introducing a disparity in only one eye. Fig. 2 shows an experiment of this kind carried out by Westheimer and Mitchell (1956). The object is moved from A to B, and requires a movement of only one eye to maintain fixation. However, both eyes make a rapid saccadic movement to $A^{\prime}$, such that the bisector of the angle of convergence passes through $B$. A convergence movement then follows which brings the fixation from $A^{\prime}$ to $B$. This returns the left eye to the original position. In fact the saccadic conjugate movement and the convergence movement begin at about the same time, but since the saccadic movement is extremely fast the effect is much the same as if the movements occurred one after the other.

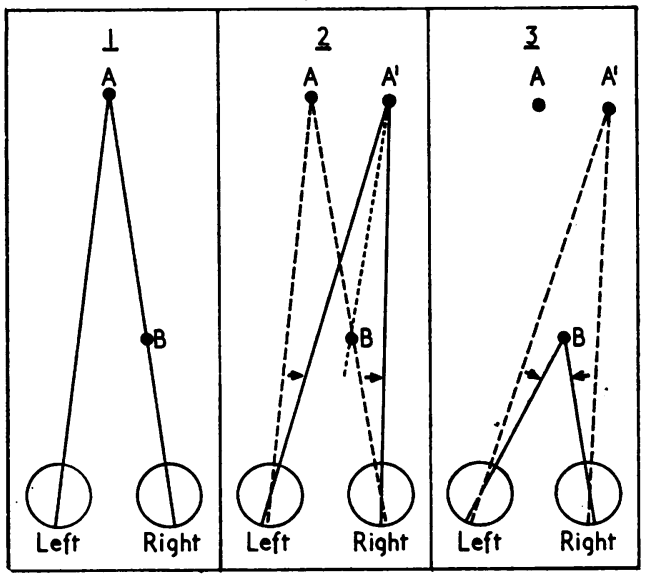

FIG. 2 Eye movements in response to a target movement

(1) Fixation at $A$

(2) Fixation moves to $A^{\prime}$

(3) Eyes converge to $B$

Source: Westheimer and Mitchell (1956)

The cue for the conjugate movement is an error in only one eye. According to the model proposed here, this should produce a movement of one half of the magnitude that would have been produced by the same error in both eyes. This prediction exactly accords with the experimental result. The saccadic movement brings the eyes into a position such that only a convergence movement is required in order to restore fixation from $A^{\prime}$ to $B$. A similar result has been obtained (Alpern, 1962, p. 91) by placing a prism before one eye during fixation. Resolution into conjugate and disjunctive components has also been shown by Yarbus (1957) for a composite movement.

The model involves a comparison of information between the two eyes. In the case of mammals, information from the right hand half of the visual field is projected to the left cerebral hemisphere and from the left hand half to the right hemisphere. Contact between the hemispheres is maintained via a series of fibre bundles, the largest of which 
is the corpus callosum. In a series of experiments on monkeys, Sperry (1964) made cuts in the corpus callosum, and observed the impairment in subsequent behaviour. Insomecaseș the operation is performed on humans in order to confine an epileptic focus to one hemi 은 sphere. The relevance of the split-brain preparation to this paper is that, although $\overrightarrow{\bar{k}}$ conjugate movement does not involve a cross-hemispherical comparison (the error signat of both eyes goes to the same hemisphere), convergence does involve a cross-hemispherica志 comparison. It might be expected that convergence would be impaired in a split-brain? subject, but not the ability to make a conjugate movement. This is assuming that the comparison is not made completely sub-cortically. Exactly the effect described, impairen ment of convergence but not conjugate movement, has been observed in a human subjectio (Westheimer and Mitchell, personal communication).

\section{Comment and summary}

The representation in control theory terms of conjugate eye movements has been extended and adapted to include convergence. The model proposed gives an unambiguous cuet for both types of movement, and makes predictions concerning a disparity created in only one eye, and split-brain subjects, which accord with the experimental results.

An earlier study (Toates, I 968 ) considered, in the language of control engineering $\vec{c}$ the relationship between accommodation of the lens and pupil size. This paper also forms part of an attempt to construct a model showing the main activities of the eye, ant in particular the interdependence between the various controlled terms.

The help and supervision received from Prof. R. Fletcher and Mr. J. Feakes of the City University, London is gratefully acknowledged. My thanks are due also to the Science Rescarch Council for providing me witlo a grant.

\section{References}

Alpern, M. (I962) "Movements of the eyes", in Davson, H., "The Eye", vol. 3, pp. 9I, 99.

Academic Press, London

campbell, f. w., and westheimer, G. (i 96o) J. Physiol. (Lond.), r51, 285

FENDER, D. H. ( I964) Scient. American, 211 , No. I, p. 24 and NYE, P. W. (I96I) Kybernetik (Berl.), I, 8 I

rashbass, c., and westheimer, g. (ig6ia) J. Physiol. (Lond.), I59, 339

$$
\text { ( г } 96 \text { I b) Ibid., r59, } 3^{6} \text { I }
$$

SPERry, R. W. (1964) Scient. American, 2ro, No. i, p. 42

STARK, L., and SHERMAN, P. M. (1957) J. Neurophysiol., 20, I 7

, TAKAHASHi, Y., and zames, G. (1965) Institute of Electronic and Electrical Enginecrs

Trans. Systems Sci. and Cyber., vol. SSC-I, p. 7.5

тоAтEs, ғ. м. (I968) "The control of the eye's intrinsic muscles", in Meas. and Control, vol. I, no. 8 "

T. 129

Westheimer, G. (i954) A.M.A. Arch. Ophthal., 52, 7 io

and Mitchell, A. м. (I956) Ibid., 55, 848

Personal communication

YARBUS, A. L. ( I957) Biophysics, 2, 679

YOUNG, L. R., and STARK, L. ( I963) "Variable feedback experiments testing a sampled data modeto

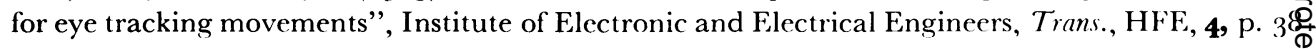

